\title{
Lack of SF3B1 R625 mutations in cutaneous melanoma
}

\author{
Bastian Schilling ${ }^{1}$, Nicola Bielefeld ${ }^{1}$, Antje Sucker ${ }^{1}$, Uwe Hillen ${ }^{1}$, Lisa Zimmer ${ }^{1}$, Dirk Schadendorf ${ }^{1}$, \\ Michael Zeschnigk ${ }^{2}$ and Klaus G Griewank ${ }^{1^{*}}$
}

\begin{abstract}
Background: Melanoma is a deadly disease affecting people worldwide. Genetic studies have identified different melanoma subtypes characterized by specific recurrently mutated genes and led to the successful clinical introduction of targeted therapies. Hotspot mutations in SF3B1 were recently reported in uveal melanoma. Our aim was to see if these mutations also occur in cutaneous melanoma.

Findings: We analyzed a cohort of 85 cutaneous melanoma including 22 superficial spreading, 24 acral-lentiginous, 36 nodular, and 3 lentigo-maligna melanomas. Exon 14 of SF3B1, containing the site of recurrent mutations described in uveal melanoma, was sequenced in all samples. Additionally, NRAS exon 1 and 2 and BRAF exon 15 were sequenced in all, KIT exons 9, 11, 13, 17, and 18 in 30 samples. High numbers of BRAF and NRAS mutations were identified with frequencies varying according to melanoma subtype. None of the samples were found to harbor a SF3B1 mutation.

Conclusions: We conclude that recurrent mutations in codon 625 of SF3B1 as reported in uveal melanoma are not present in most types of cutaneous melanoma. This highlights the genetic differences between cutaneous and uveal melanoma and the need for subtype specific therapeutic approaches.
\end{abstract}

Keywords: Melanoma, SF3B1, Cancer genetics, Dermatology

\section{Introduction}

Malignant melanoma is a devastating disease worldwide $[1,2]$. Curative management of melanoma is limited to the stage of localized disease. Once metastatic spread has occurred, prognosis of patients is poor. However, a number of promising new treatment regimens have been introduced recently, showing for the first time a therapy induced increase in overall survival [3,4].

Over the last couple of decades a number of genetic alterations have been identified in melanoma. Activating driver mutations in genes such as NRAS [5] and BRAF [6] were identified in cutaneous melanoma. Losses of tumor suppressors such as CDKN2A and PTEN have been well documented [7]. In uveal melanoma a different set of genes shows recurrent mutations, including GNAQ and GNA11 [8,9], with activating mutations as well as in BAP1 [10] showing inactivating mutations. The distinct

\footnotetext{
* Correspondence: klaus.griewank@uk-essen.de

'Department of Dermatology, University Hospital, University Duisburg-Essen, Hufelandstrasse 55, Essen 45147, Germany

Full list of author information is available at the end of the article
}

mutation profiles of cutaneous and uveal melanoma are striking and support a model of different developmental pathways. However there is some overlap in tumor biology as $\sim 80 \%$ of blue nevi, which are benign melanocytic tumors of the skin, also harbor GNAQ or GNA11 mutations, [8] and BAP1 mutations can be found in both cutaneous nevi and cutaneous melanoma [11-14].

Both genetic and immunohistological assays are becoming more and more relevant in determining the dignity and prognosis of melanocytic neoplasms [15-18]. Further refining which biomarkers are relevant in which settings should allow pathologists and clinicians to make more detailed diagnostic calls, leading to appropriate follow-up and treatment decisions.

Recently a recurrent mutation hotspot in SF3B1 affecting codon 625 was found in $18.6 \%$ of uveal melanoma [19]. SF3B1 mutations had been previously detected in myeloid malignancies such as CLL (chronic lymphoid leukemia) and MDS (myelodysplastic syndrome) [20,21] and also reported in breast cancer [22]. SF3B1 is a splice factor, with mutations expected to result in altered pre
C Biomed Central

(c) 2013 Schilling et al.; licensee BioMed Central Ltd. This is an Open Access article distributed under the terms of the Creative Commons Attribution License (http://creativecommons.org/licenses/by/2.0), which permits unrestricted use, distribution, and reproduction in any medium, provided the original work is properly cited. 
mRNA splicing. However the exact target of altered splicing is unknown and might be cell type dependent [22].

The goal of our study was to analyze if SF3B1 mutations not only play a role in uveal, but also in cutaneous melanoma.

\section{Material and methods}

\section{Sample selection and histopathology}

Cutaneous melanoma samples were obtained from the tumor bank of the Department of Dermatology, University Hospital, University Duisburg-Essen. The study was done with approval of the local ethics committee of the University of Duisburg-Essen.

\section{DNA isolation}

$10 \mu \mathrm{m}$-thick sections were cut from formalin-fixed, paraffinembedded tumor tissues. The sections were deparaffinized and manually microdissected according to standard procedures. Genomic DNA was isolated using the QIAamp DNA Mini Kit (Qiagen, Hilden, Germany) according to the manufacturer's instructions.

\section{Direct (Sanger) sequencing}

Nested PCR was performed to amplify BRAF exon 15 and NRAS exon 1 and 2 and sequenced as previously described [23]. Sequencing of KIT exons 9, 11, 13, 17, and 18 was performed similarly. The first 120 base pairs of SF3B1 exon 14 (covering codons 603-641) were sequenced using the forward primer - TGTTTACATTTTAGGCTG CTGGT and reverse primer - GCCAGGACTTCTTGCT TTTG. After purification with the QIAquick PCR Purification Kit (Qiagen) PCR products were used as templates for sequencing in both directions. The sequencing chromatogram files were examined, and mutations were identified using Chromas software (version 2.01, University of Sussex, Brighton, United Kingdom).

\section{Results}

\section{Sample cohort}

The cohort included tumors from 51 males and 34 females, including 22 superficial spreading, 24 acral-lentiginous, 36 nodular, and 3 lentigo-maligna melanomas, with an average
Breslow tumor thickness of $3.62 \mathrm{~mm}$. The average thickness between subtypes varied; acral-lentiginous melanoma $($ ALM $)=4.54 \mathrm{~mm}$, nodular melanoma $(\mathrm{NM})=4.47 \mathrm{~mm}$, superficial spreading melanoma $(\mathrm{SSM})=1.9 \mathrm{~mm}$ and lentigo maligna melanoma $(\mathrm{LMM})=0.53 \mathrm{~mm}$.

\section{NRAS, BRAF, and KIT mutations}

We analyzed 85 cutaneous melanomas in total. BRAF Exon 15 and NRAS Exon 1 and 2 were analyzed for presence of mutations by Sanger sequencing (Table 1). We identified 36 BRAF mutations (35 p.V600E, 1 p.V600K) and 19 NRAS mutations (11 p.Q61K, 3 p.Q61L, 5 p.Q61R). In total, $65 \%$ of tumors showed either a BRAF or NRAS mutation (42\% BRAF, 22\% NRAS). As reported previously, the mutations were found to be mutually exclusive. Prevalence of $B R A F$ and NRAS mutations varied by histologic subtype; ALM - 33\% BRAF, 13\% NRAS, NM - 42\% BRAF, 25\% NRAS, and SSM - 60\% BRAF, 23\% NRAS mutations. Presence of KIT mutations was analyzed in 30 cases. 18 of these were in ALM in which the highest percentage of KIT mutations would be expected (18/24 ALM total $=75 \%)$ [24-26]. One ALM sample was found to harbor a p.N505H (c.1513A >C) mutation/variant. We further analyzed $7 \mathrm{NM}, 4 \mathrm{SSM}$, and $1 \mathrm{LMM}$, not identifying any KIT mutations.

\section{SF3B1 analysis}

The first 120 base pairs of exon 14, containing the location of the known hotspot mutation at codon 625 , were sequenced in all 85 samples. In four samples amplification failed or sequence reads were ambiguous. None of the remaining 81 samples showed a mutation in SF3B1 as seen in a control sample from a uveal melanoma (Figure 1).

\section{Discussion}

Genetic classification of different melanoma subtypes has become very important, especially with the introduction of effective therapies targeting genetic alterations such as BRAF [3,4] and KIT mutations [25]. A detailed understanding of the genetic events occurring in different tumors will most likely prove critical to further

Table 1 Table of sequencing results

\begin{tabular}{|c|c|c|c|c|c|c|c|c|c|c|c|}
\hline & \multicolumn{7}{|c|}{ Oncogene mutation status } & \multicolumn{4}{|c|}{ SF3B1 } \\
\hline & \multirow{2}{*}{$\begin{array}{l}\text { Total } \\
\text { Count }\end{array}$} & \multicolumn{2}{|c|}{ WT } & \multicolumn{2}{|c|}{ BRAF V600 } & \multicolumn{2}{|c|}{ NRAS Q61 } & \multicolumn{2}{|c|}{ NA } & \multicolumn{2}{|c|}{ WT } \\
\hline & & Count & $\%$ & Count & $\%$ & Count & $\%$ & Count & $\%$ & Count & $\%$ \\
\hline SSM & 22 & 4 & $18.2 \%$ & 13 & $59.1 \%$ & 5 & $22.7 \%$ & 1 & $4.5 \%$ & 21 & $95.5 \%$ \\
\hline NM & 36 & 12 & $33.3 \%$ & 15 & $41.7 \%$ & 9 & $25.0 \%$ & 3 & $8.3 \%$ & 33 & $91.7 \%$ \\
\hline ALM & 24 & 13 & $54.2 \%$ & 8 & $33.3 \%$ & 3 & $12.5 \%$ & 0 & $.0 \%$ & 24 & $100.0 \%$ \\
\hline LMM & 3 & 1 & $33.3 \%$ & 0 & $.0 \%$ & 2 & $66.7 \%$ & 0 & $.0 \%$ & 3 & $100.0 \%$ \\
\hline
\end{tabular}

WT, Wildtype; SSM, Superficial spreading melanoma; NM, Nodular melanoma; ALM, Acral lentiginous melanoma; $L M M$, Lentigo maligna melanoma. NA, Not available (amplification failed or sequence reads were ambiguous). 


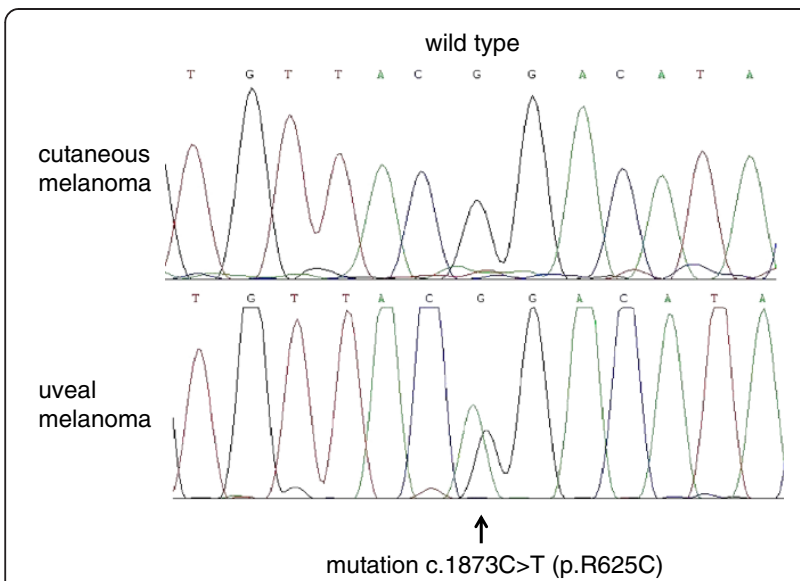

Figure 1 Example of SF3B1 sequencing. Shown are representative examples of SF3B1 exon 14 sequencing, with a wild type sequence of a cutaneous melanoma on the top and a corresponding codon 625 mutation of a uveal melanoma on the bottom.

improving the therapeutic modalities for metastasized melanoma patients.

The distribution of activating oncogene mutations in $B R A F$ and NRAS in our cohort is comparable to those reported elsewhere [7]. Overall 65\% of melanoma had a $B R A F$ or NRAS mutation in a mutually exclusive pattern. Of the three melanoma subtypes analyzed in considerable numbers (SSM, NM, ALM), percentages of BRAF and NRAS mutations combined were highest in SSM reaching $82 \%$, lower in NM with $67 \%$ and lowest in ALM with $46 \%$. The KIT mutation/variant identified in an ALM sample led to a p.N505V change. This is not reported to be a frequent mutation in cutaneous melanoma [27]. However p.N505H (c.1513A > C) is listed as a "variant of unknown origin" in a gastrointestinal stromal tumor in the COSMIC database [28]. The cutaneous ALM sample lacked mutations in BRAF or NRAS which could support a potential relevance, as typically KIT mutations are found to be mutually exclusive with $B R A F$ and NRAS mutations [26]. The p.N505H (c.1513A > C) change could however also represent a rare germ-line variant, which we could not check as corresponding normal DNA was not available.

We obtained high quality sequencing results allowing analysis of exon 14 and in particular codon 625 of SF3B1 in 81 samples and found no mutations. This argues against a major role for SF3B1 in tumorigenesis or progression of cutaneous melanoma. In uveal melanomas, mutations were primarily found in tumors with a favorable prognosis [19]. Future studies could analyze if SF3B1 mutations occur in benign cutaneous melanocytic tumors (nevi) or potentially in sites other than in codon 603-641 of exon 14 of SF3B1.

In recent years genetic analyses identified a number of key genes involved in melanoma formation or progression.
Interestingly, almost all of those described in cutaneous melanoma are not known to be relevant in uveal melanoma [29,30]. In contrast, genetic alterations in uveal melanoma such as GNAQ and GNA11 mutations were also found in selected cases of cutaneous melanoma and are frequently found in blue nevi (benign cutaneous melanocytic tumors) [9]. BAP1 inactivating mutations are found in cutaneous nevi and melanoma, although considerably less frequently than in uveal melanoma [12]. Our current study would signify that SF3B1 mutations, occurring in almost $20 \%$ of uveal melanoma, [19] do not play a major role in cutaneous melanoma. We believe this highlights once more the genetic differences between uveal and cutaneous melanoma and the need for development of melanoma subtype specific therapies.

\section{Abbreviations}

ALM: Acral-lentiginous melanoma; SSM: Superficial spreading melanoma; NM: Nodular melanoma; LMM: Lentigo maligna melanoma.

\section{Competing interests}

Dirk Schadendorf is on the advisory board or has received honararia from Roche, Genetech, Novartis, Amgen, GSK, BMS, Boehringer Ingelheim, and Merck. All other authors have nothing to declare.

\section{Authors' contributions}

Literature search: BS, LZ, MZ, DS, KGG Study design: BS, AS, DS, MZ, KGG Data collection: NB, AS, BS, UH, KGG Data analysis: BS, NB, AS, KGG Data interpretation: BS, LZ, DS, MZ, UH KGG Manuscript writing: all authors. All authors read and approved the final manuscript.

\section{Acknowledgments}

We would like to thank Iris Moll, Sabine Prass, and Marion Schwamborn for their excellent technical support.

\section{Financial disclosure}

The research was supported by a grant from the MERCUR-Stiftung. The funders had no role in study design, data collection and analysis, decision to publish, or preparation of the manuscript.

\section{Author details}

${ }^{1}$ Department of Dermatology, University Hospital, University Duisburg-Essen, Hufelandstrasse 55, Essen 45147, Germany. '2Department of Human Genetics, University Hospital, University Duisburg-Essen, Hufelandstrasse 55, Essen 45147, Germany.

Received: 4 April 2013 Accepted: 16 May 2013

Published: 21 May 2013

\section{References}

1. Siegel R, Naishadham D, Jemal A: Cancer statistics, 2012. CA Cancer J Clin 2012, 62:10-29.

2. Flaherty KT, Hodi FS, Fisher DE: From genes to drugs: targeted strategies for melanoma. Nat Rev Cancer 2012, 12:349-361.

3. Chapman PB, Hauschild A, Robert C, Haanen JB, Ascierto P, Larkin J, Dummer R, Garbe C, Testori A, Maio M, et al: Improved survival with vemurafenib in melanoma with BRAF V600E mutation. $N$ Engl J Med 2011, 364:2507-2516.

4. Flaherty KT, Infante JR, Daud A, Gonzalez R, Kefford RF, Sosman J, Hamid O, Schuchter L, Cebon J, Ibrahim N, et al: Combined BRAF and MEK inhibition in melanoma with BRAF V600 mutations. N Engl J Med 2012, 367:1694-1703.

5. Ball NJ, Yohn JJ, Morelli JG, Norris DA, Golitz LE, Hoeffler JP: Ras mutations in human melanoma: a marker of malignant progression. J Invest Dermatol 1994, 102:285-290. 
6. Davies H, Bignell GR, Cox C, Stephens P, Edkins S, Clegg S, Teague J, Woffendin H, Garnett MJ, Bottomley W, et al: Mutations of the BRAF gene in human cancer. Nature 2002, 417:949-954.

7. Curtin JA, Fridlyand J, Kageshita T, Patel HN, Busam KJ, Kutzner H, Cho KH, Aiba S, Brocker EB, LeBoit PE, et al: Distinct sets of genetic alterations in melanoma. N Engl J Med 2005, 353:2135-2147.

8. Van Raamsdonk CD, Bezrookove V, Green G, Bauer J, Gaugler L, O'Brien JM, Simpson EM, Barsh GS, Bastian BC: Frequent somatic mutations of GNAQ in uveal melanoma and blue naevi. Nature 2009, 457:599-602.

9. Van Raamsdonk CD, Griewank KG, Crosby MB, Garrido MC, Vemula S, Wiesner T, Obenauf AC, Wackernagel W, Green G, Bouvier N, et al: Mutations in GNA11 in uveal melanoma. N Engl J Med 2010, 363:2191-2199.

10. Harbour JW, Onken MD, Roberson ED, Duan S, Cao L, Worley LA, Council ML, Matatall KA, Helms C, Bowcock AM: Frequent mutation of BAP1 in metastasizing uveal melanomas. Science 2010, 330:1410-1413.

11. Wiesner T, Murali R, Fried I, Cerroni L, Busam K, Kutzner H, Bastian BC: A distinct subset of atypical Spitz tumors is characterized by BRAF mutation and loss of BAP1 expression. Am J Surg Pathol 2012, 36:818-830.

12. Wiesner T, Obenauf AC, Murali R, Fried I, Griewank KG, Ulz P, Windpassinger C, Wackernagel W, Loy S, Wolf I, et al: Germline mutations in BAP1 predispose to melanocytic tumors. Nat Gen 2011, 43:1018-1021.

13. Carbone M, Ferris LK, Baumann F, Napolitano A, Lum CA, Flores EG, Gaudino G, Powers A, Bryant-Greenwood P, Krausz T, et al: BAP1 cancer syndrome: malignant mesothelioma, uveal and cutaneous melanoma, and MBAITs. J Trans Med 2012, 10:179.

14. Njauw CN, Kim I, Piris A, Gabree M, Taylor M, Lane AM, DeAngelis MM, Gragoudas E, Duncan LM, Tsao H: Germline BAP1 inactivation is preferentially associated with metastatic ocular melanoma and cutaneous-ocular melanoma families. PLoS One 2012, 7:e35295.

15. Moore MW, Gasparini R: FISH as an effective diagnostic tool for the management of challenging melanocytic lesions. Diagn Pathol 2011, 6:76.

16. Bauer J, Bastian BC: Distinguishing melanocytic nevi from melanoma by DNA copy number changes: comparative genomic hybridization as a research and diagnostic tool. Dermatol Ther 2006, 19:40-49.

17. Nodin B, Fridberg M, Jonsson L, Bergman J, Uhlen M, Jirstrom K: High MCM3 expression is an independent biomarker of poor prognosis and correlates with reduced RBM3 expression in a prospective cohort of malignant melanoma. Diagn Pathol 2012, 7:82.

18. Schimming $\Pi$, Grabellus F, Roner M, Pechlivanis S, Sucker A, Bielefeld N, Moll I, Schadendorf D, Hillen U: pHH3 immunostaining improves interobserver agreement of mitotic index in thin melanomas. Am $J$ Dermatopathol 2012, 34:266-269.

19. Harbour JW, Roberson ED, Anbunathan H, Onken MD, Worley LA, Bowcock AM: Recurrent mutations at codon 625 of the splicing factor SF3B1 in uveal melanoma. Nat Gen 2013, 45(2):133-135. doi:10.1038/ng.2523. Epub 2013 Jan 13.

20. Papaemmanuil E, Cazzola M, Boultwood J, Malcovati L, Vyas P, Bowen D, Pellagatti A, Wainscoat JS, Hellstrom-Lindberg E, Gambacorti-Passerini C, et al: Somatic SF3B1 mutation in myelodysplasia with ring sideroblasts. N Eng J Med 2011, 365:1384-1395.

21. Quesada V, Conde L, Villamor N, Ordonez GR, Jares P, Bassaganyas L, Ramsay AJ, Bea S, Pinyol M, Martinez-Trillos A, et al: Exome sequencing identifies recurrent mutations of the splicing factor SF3B1 gene in chronic lymphocytic leukemia. Nat Gen 2012, 44:47-52.

22. Ellis MJ, Ding L, Shen D, Luo J, Suman VJ, Wallis JW, Van Tine BA, Hoog J, Goiffon RJ, Goldstein TC, et al: Whole-genome analysis informs breast cancer response to aromatase inhibition. Nature 2012, 486:353-360.

23. Houben R, Becker JC, Kappel A, Terheyden P, Brocker EB, Goetz R, Rapp UR: Constitutive activation of the Ras-Raf signaling pathway in metastatic melanoma is associated with poor prognosis. J Carcinogen 2004, 3:6

24. Beadling C, Jacobson-Dunlop E, Hodi FS, Le C, Warrick A, Patterson J, Town A, Harlow A, Cruz F 3rd, Azar S, et al: KIT gene mutations and copy number in melanoma subtypes. Clin Cancer Res J Am Assoc Cancer Res 2008, 14:6821-6828

25. Carvajal RD, Antonescu CR, Wolchok JD, Chapman PB, Roman RA, Teitcher J Panageas KS, Busam KJ, Chmielowski B, Lutzky J, et al: KIT as a therapeutic target in metastatic melanoma. JAMA 2011, 305:2327-2334.

26. Curtin JA, Busam K, Pinkel D, Bastian BC: Somatic activation of KIT in distinct subtypes of melanoma. J Clin Oncol J Am Soc Clin Oncol 2006, 24:4340-4346.
27. Garrido MC, Bastian BC: KIT as a therapeutic target in melanoma. J Invest Dermatol 2010, 130:20-27.

28. Forbes SA, Bindal N, Bamford S, Cole C, Kok CY, Beare D, Jia M, Shepherd R, Leung $\mathrm{K}$, Menzies A, et al: COSMIC: mining complete cancer genomes in the Catalogue of Somatic Mutations in Cancer. Nucleic Acids Res 2011, 39:D945-950.

29. Krauthammer M, Kong Y, Ha BH, Evans P, Bacchiocchi A, McCusker JP, Cheng E, Davis MJ, Goh G, Choi M, et al: Exome sequencing identifies recurrent somatic RAC1 mutations in melanoma. Nat Gen 2012, 44:1006-1014.

30. Hodis E, Watson IR, Kryukov GV, Arold ST, Imielinski M, Theurillat JP, Nickerson E, Auclair D, Li L, Place C, et al: A landscape of driver mutations in melanoma. Cell 2012, 150:251-263.

doi:10.1186/1746-1596-8-87

Cite this article as: Schilling et al:: Lack of SF3B1 R625 mutations in cutaneous melanoma. Diagnostic Pathology 2013 8:87.

\section{Submit your next manuscript to BioMed Central and take full advantage of:}

- Convenient online submission

- Thorough peer review

- No space constraints or color figure charges

- Immediate publication on acceptance

- Inclusion in PubMed, CAS, Scopus and Google Scholar

- Research which is freely available for redistribution

Submit your manuscript at www.biomedcentral.com/submit
C) Biomed Central 